\title{
Douglas Sinn
}

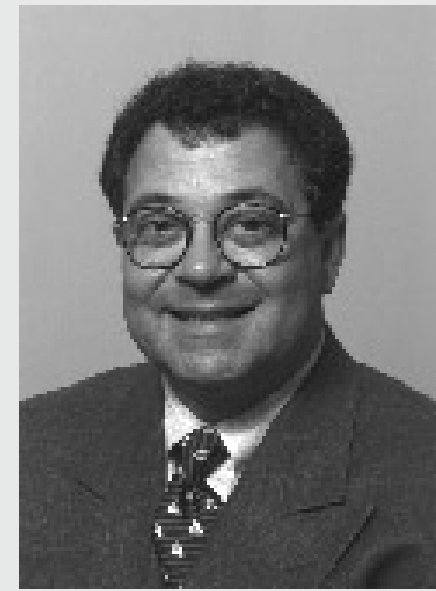

Chefe da divisão de Cirurgia Oral e Maxillofacial, do departamento de cirurgia, da UTSouthwestern Medical School; Dallas/Texas.

- Diplomado com Board da Associação Americana de Cirurgia Oral e Maxillofacial.

- Chefe do Comitê de Fellowship da Fundação Americana de Cirurgia Oral e Maxillofacial.

- Editor do periódico Selected Readings in Oral and Maxillofacial Surgery.

- Chefe do setor de cirurgia Oral e Maxilofacial do Parkland Memorial Hospital, Texas.

- Chefe do Centro de atendimento médico médico para crianças, no Hospital da Universidade Zale Lipshy, Texas.

- Autor de vários artigos, livros e capítulos de livros sobre cirurgia Oral e Maxilofacial.

Uma das maiores emoções na vida de qualquer profissional é a de conhecer e poder trabalhar junto de seus ídolos, ou seja, daquelas pessoas que fizeram e ainda fazem história na área de sua atuação profissional. Eu tive a felicidade de tornar este sonho realidade e aproveito esta oportunidade para compartilhar um pouco do que aprendi com um famoso professor. Professor este, que no campo profissional é um dos melhores e mais reconhecidos do mundo na sua área, e que no campo pessoal trata-se de uma pessoa simples, humilde e que está sempre disposta a ajudar as pessoas (pacientes) que por ventura precisem dos seus cuidados.

A área de atuação em questão é a Cirurgia e Traumatologia Buco-Maxilo-Facial, e o ídolo é o Professor Doutor Douglas Sinn, consagrado cirurgião, que ocupa uma das cadeiras de chefe em um dos melhores serviços de Cirurgia e Traumatologia Buco-Maxilo-Facial do Mundo; o serviço de Cirurgia Buco-Maxilo-Facial da Southwestern Medical School na Universidade do Texas (Dalas). Serviço o qual, tive o prazer de visitar e atuar como Fellowship resident durante alguns meses do ano passado (2003), graças a meu grande amigo, professor e orientador Dr. Mário Gabrielli (UNESP - Araraquara) que tornou possível a realização deste "sonho", por intermédio de seu amigo pessoal o Professor Dr. Edward Ellis III (Dallas).

O Professor Douglas Sinn é conhecido por seus inúmeros artigos publicados na literatura científica internacional, participação em livros e por sua experiência singular em cirurgia Buco-Maxilo-Facial. Experiência a qual pude testemunhar, estando em campo juntamente com o professor em várias de suas cirurgias (cirurgias ortognáticas, reconstruções complexas de ATM, distração osteogênica, cranioplastias, etc.). Dr. Sinn atende em sua clínica particular e nos Hospitais Parkland Memorial Hospital, Childrens Hospital e Zale Lipsy University Hospital, além de atender no ambulatório destes hospitais e na clínica da graduação de odontologia, onde é professor titular da cadeira de cirurgia buco-maxilo-facial.

No decorrer da entrevista com o Dr. Sinn ele nos conta um pouco da sua trajetória pessoal como cirurgião e responde algumas perguntas a respeito de cirurgia, formuladas por mim e pelo Dr. Maurício Bento da Silva (amigo e colega de profissão).

Aproveitamos para agradecer a oportunidade nos dada pela revista Dentalpress e ao Professor Douglas Sinn que nos concedeu o privilégio desta entrevista.

Marcelo Silva Monnazzi e Maurício Bento da Silva 
1) Fale-nos sobre sua história como cirurgião bucal e maxilofacial? Marcelo Monnazzi

Minha história pessoal como cirurgião bucal e maxilofacial começou em 1970 ao iniciar minha residência na Universidade do Centro Médico do Sudoeste do Texas/ Hospital Memorial Parkland. Me transferi para o Parkland ao terminar a escola odontológica na região do meio oeste dos Estados Unidos. Fiquei fascinado pelo Dr. Robert V. Walker e pela outra faculdade na Universidade do Texas, a qual incluía os Drs. James Bertz e Bruce Epker. Após aproximadamente dois anos de treinamento, ficou evidente que eu pretendia permanecer como um cirurgião bucal e maxilofacial na arena acadêmica. Isto deveu-se, principalmente, à faculdade, e eu havia completado um ano de pesquisa sobre a doença da glândula salivar, sob a direção do Dr. Bruce Epker, o que me tornou cada vez mais atraído e interessado em fazer parte da especialidade. Naquela época, o Parkland constituía principalmente um serviço de trauma e de cirurgia bucal pediátrica, e nosso nível de participação era muito elevado. Terminei meu treinamento em 1974 e me tornei parte integrante da faculdade de odontologia da Universidade do Texas. Sob a direção do Dr. Robert V. Walker, progredi rapidamente para Professor Assistente e Professor Associado, e dez anos após ter ingressado na faculdade fui nomeado Professor e Presidente da Divisão de Cirurgia Bucal e Maxilofacial, isto em 1984. Tomei posse como professor tempo integral e me tornei muito ativo em cirurgia bucal e maxilofacial.

\section{2) Quem é seu principal mestre em cirurgia e por que? Maurício Bento da Silva.}

Meu principal mestre na especialidade é Robert V. Walker porque foi meu mentor, diretor, líder, professor, amigo e modelo. Ele sempre será o homem que eu mais admiro e considero em nossa especialidade, e também meu melhor amigo.
3) Por que você foi para a escola médica? Caso tenha ido. Se não foi, acredita ser importante para os cirurgiões bucais freqüentarem a escola médica? Marcelo Monnazzi

Não freqüentei a escola médica. Completei minha escola odontológica e fui direto para a cirurgia bucal. $\mathrm{Na}$ época que me uni à especialidade, a ênfase em educação médica não era muito significante. Entretanto, como muitos anos se passaram desde então, mudei de idéia e acredito que a escola médica constitui parte importante de nossa especialidade. Não acredito que ela nos torne melhores cirurgiões, mas com certeza nos prepara melhor para lidar com o paciente, o que não é adquirido na educação odontológica.

\section{4) Você utiliza algum software para auxiliá-lo no planejamento do tratamento da cirurgia ortognática? É seguro? Maurício Bento}

O programa de software que tenho utilizado no plano do tratamento da cirurgia ortognática é o Photoshop para a porção estética do planejamento. Em minha opinião ele é artístico, mas não 100\% seguro, porém com um serviço de orientação ao cliente muito bom. Os pacientes gostam dele e muitas vezes consegue-se vender um caso que de outra forma não seria vendável.

5) Quais são seus passos no planejamento da cirurgia ortognática? Quais os diálogos que o médico deve ter com seus pacientes? 0 que é mais importante analisar antes da cirurgia? Quais as medidas mais freqüentemente utilizadas para a cirurgia, etc.? Marcelo Monnazzi

O plano de tratamento da cirurgia ortognática constitui um dos aspectos mais difíceis de nossa especialidade. Primeiramente, é extremamente importante ter o diagnóstico correto para seu paciente, de modo que se possa desenvolver um plano perfeito. O diálogo com o ortodontista, tanto antes, quanto durante e após o acompanhamento ortodôntico antes do tratamento cirúrgico é muito importante. Exige-se do ci- 
rurgião bucal e maxilofacial um conhecimento amplo sobre ortodontia para se comunicar com o ortodontista em um nível significativo e compreensível para o próprio ortodontista com relação ao cuidado do paciente. É importante observar todos os aspectos do paciente do ponto de vista clínico, assim como sob as perspectivas dentária e esquelética. A estética é o ponto mais primordial de todo o plano de tratamento e cria limites para a cirurgia. Sem uma análise clínica satisfatória, pode-se desenvolver planos de tratamento com resultados não muito satisfatórios para o paciente. As alterações esqueléticas apresentam limites criados pelo tecido mole. A parte mais importante da Ortodontia é preparar os pacientes para os movimentos cirúrgicos com a melhor oclusão possível. Não enfatizo muito os números no plano de tratamento. Faço algumas mensurações e julgo a aparência do paciente e os efeitos que os movimentos esqueléticos terão sobre o tecido mole.

\section{6) Qual sua opinião pessoal sobre a fixação} rígida interna nas cirurgias maxilares e mandibulares? Marcelo Monnazzi

Não utilizo o bloqueio maxilomandibular durante minhas cirurgias, mas sempre uso a fixação interna rígida (FRI). Utilizo placas de titânio e algumas placas com reabsorção, dependendo do procedimento e do plano.

7) Qual a melhor maneira de evitar 0 deslocamento condilar e/ou torque durante a cirurgia mandibular, especialmente na osteotomia sagital do ramo? Marcelo Monnazzi

A osteotomia sagital constitui uma das cirurgias mais difíceis na esfera da cirurgia ortognática. É extremamente importante posicionar o segmento condilar de forma correta. Há documentação consistente na literatura de que os aparelhos de posicionamento condilar têm pouco valor. Acredito que a melhor maneira é fixar o côndilo em posição passiva, a saber, plana e confortável, mas não excessivamente firme. Posiciono o segmento proximal e fixo firmemente o segmento proximal ao segmento distal com uma placa rígida lateral de titânio de $2 \mathrm{~mm}$ da SSRO e parafusos unicorticais de $5 \mathrm{~mm}$.

\section{8) Você prefere remover os terceiros molares} impactados antes da cirurgia ortognática? Por que? Maurício Bento da Silva

Utilizando-se a técnica de fixação descrita na resposta à questão anterior, os terceiros molares não precisam ser removidos antes da osteotomia sagital do ramo, visto que a porção média do segmento distal não é utilizada para a técnica de estabilização.

9) Qual a melhor manobra para assegurar que o côndilo esteja na melhor posição durante a cirurgia mandibular antes da fixação? Marcelo Monnazzi

O posicionamento do côndilo é realizado antes da fixação rígida. O côndilo deve ser empurrado para a região superior de forma confortável, mas não totalmente firme. Deve-se tomar cuidado para que, com os dentes amarrados juntos, esta posição seja absolutamente correta. Uma placa interoclusal pré-operatória é utilizada para posicionar os dentes de forma que um melhor controle condilar possa ser alcançado.

10) Qual sua opinião sobre a cirurgia condilar? Quando é indicada? Você acredita que possa ser realizada simultaneamente com a cirurgia ortognática? Por que? Maurício Bento

Acredito extremamente na cirurgia da articulação temporomandibular quando indicada, isto é, em osteoartrose avançada, anquilose e desordens internas. Raramente recomendaria a realização da cirurgia ortognática juntamente com a cirurgia da ATM. Isto só seria considerado nas piores das circunstâncias. A combinação desses dois procedimentos pode tornar-se extremamente perigosa para o resultado. 
11) O deslocamento do disco da ATM deve ser sempre tratado por meio de cirurgia? Em sua opinião, quais os outros tipos de tratamento que podem fornecer resultados satisfatórios? Maurício Bento

Tenho a opinião de que um disco deslocado para a região anterior consiste na única indicação verdadeiramente cirúrgica para a cirurgia direta do disco, visto que está relacionada com o côndilo mandibular. O reposicionamento do disco em pacientes com travamento no fechamento e uma evidência clara de deslocamento crônico com função limitada e dor, pode fornecer um resultado razoavelmente previsível. O tratamento que utilizo mais freqüentemente é uma abordagem pré-auricular, uma artroplastia com dano mínimo para as superfícies condilares, e o reposicionamento do disco com uma âncora estabilizadora.

12) Qual a melhor abordagem para a cirurgia da ATM? Qual a incidência de paralisia do nervo facial? Os danos são sempre temporários ou há a paralisia permanente do nervo? Qual o melhor tratamento ou terapia no caso de uma lesão permanente do nervo facial? Marcelo Monnazzi

Para a cirurgia da ATM utilizo a abordagem pré-auricular modificada, que permite uma menor chance de dano para o VII nervo craniano. Há danos temporários aos nervos faciais, de estiramento à trauma. Recomendo o uso de um estimulador de nervo ou de um monitor de impulso nervoso em pacientes submetidos a diversas cirurgias, para reduzir os casos de dano ao nervo facial. No caso de uma lesão ou dano é melhor não realizar outro tratamento na área até que ocorra a reinervação. Esta reinervação ocorrerá em três ou seis meses quando o dano estiver posterior ao canto lateral do olho. É muito raro não ocorrer uma recuperação total.

\section{3) Você já esteve no Brasil? Maurício Bento}

Estive no Brasil muitas vezes. Gosto de seu país, do povo e de seu lindo cenário. Considero os cirurgiões bucais e maxilofaciais brasileiros meus melhores amigos.

14) Em sua opinião, qual é o futuro para os procedimentos da ATM? Haverá alguma mudança drástica nos próximos 5 ou 10 anos? Teremos mais tratamentos cirúrgicos, ou não-cirúrgicos? Marcelo Monnazzi

Como um cirurgião bucal e maxilofacial, acredito firmemente que os procedimentos cirúrgicos da ATM serão necessários no futuro. Certamente, não há nenhum outro tratamento para os pacientes com desordens internas, com anquilose, e para aqueles com doenças avançadas, incluindo a anquilose. Será necessário algum tipo de reposicionamento total da articulação. Acredito que a tecnologia foi aprimorada nos últimos quinze anos e continuará dessa forma nos próximos quinze anos com relação às próteses da ATM. Outros procedimentos cirúrgicos da ATM não mudaram muito nos últimos anos. A cirurgia da ATM continuará a ser necessária para o travamento no fechamento em paciente com artrite severa, ou para aqueles pacientes com um processo que tenha causado um dano irreparável ao disco.

Marcelo Silva Monnazzi *

Maurício Bento da Silva **

* Cirurgião Dentista formado pela Universidade do Sagrado Coração - Bauru; Buco-Maxilo formado pelo Serviço de Cirurgia e Traumatologia Bucomaxilo-Facial de Araraquara - UNESP; Fellowship na UTSouthwestern Medical School em Dallas

** Cirurgião Dentista, Estomatologista formado pelo Hospital do Cancêr - São Paulo; residente do Serviço de Cirurgia e Traumatologia Buco-Maxilo-Facial de Maringá - PR. 